\title{
Tackling the heart sink symptom ERS guidelines on chronic cough
}

Cough is probably the most common symptom of medical importance. Chronic cough, as defined as a cough lasting $>8$ weeks, afflicts large numbers of people within the European Union
(EU). The European Community Respiratory Health Survey reports that in excess of $10 \%$ of the young adult population complain of chronic cough. We all know that chronic cough is one of

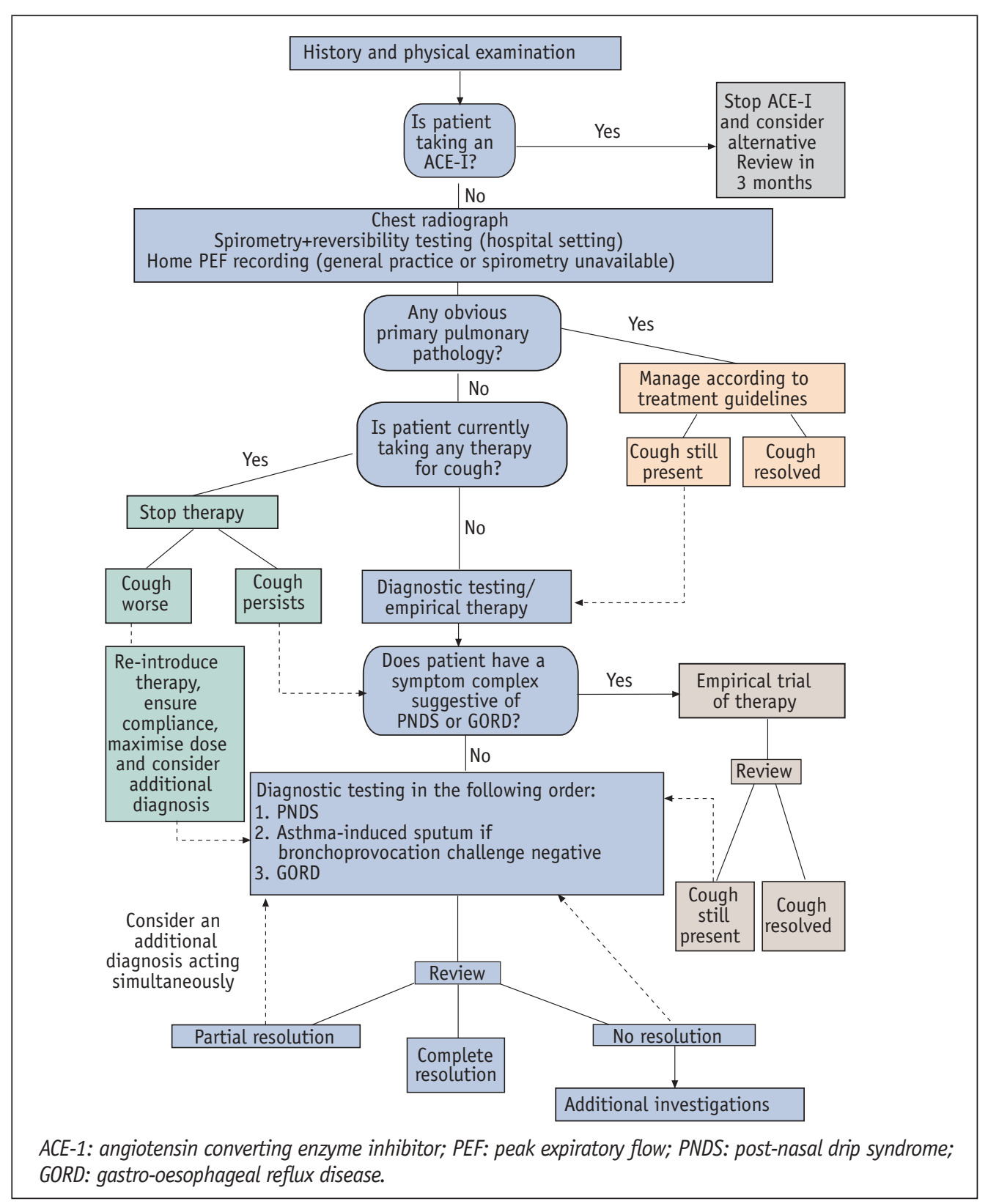


